\title{
Mass-balance terms revisited
}

\author{
J. Graham COGLEY \\ Department of Geography, Trent University, Peterborough, Ontario K9J 7B8, Canada \\ E-mail: gcogley@trentu.ca
}

\begin{abstract}
For 40 years Anonymous (J. Glaciol., 8(52), 1969) has been the effective standard of glacier mass-balance terminology. It grew out of a concern for clarity in the communication of information, and has guided thinking about mass balance in many ways. Certain ambiguities and gaps in its conceptualization have become more evident with the passage of time, and some have been aggravated by ad hoc extensions of and deviations from the standard. Methodological progress means that a review of the terminology of Anonymous (1969) is now timely, and a forthcoming glossary to be published by the International Association of Cryospheric Sciences addresses this need. There are good reasons for being concerned about clear terminology, but consistent usage by the members of a large community cannot be secured other than by consensus.
\end{abstract}

\section{INTRODUCTION}

Anonymous (1969) has long been the effective standard of mass-balance terminology, its stated purpose being 'to reduce the ambiguity and confusion caused by the use of a large number of alternate schemes and definitions'. The aim of this paper is to place Anonymous (1969) in historical context, to discuss briefly some of the residual ambiguities and gaps in Anonymous's conceptualization of glacier mass balance, and to describe a recent attempt to bring this living standard up to date. The concluding section is an attempt to place work on terminology in perspective.

\section{HISTORY}

Windham and Martel (1744) are believed to have been the first to use the word glacier in an English document. (The identity of Windham, described only as 'an English gentleman', is established by Rowlinson 1998.) Their account of a visit to the glaciers of the Chamonix valley, Savoy, France, includes remarks on subglacial hydrology, on local accounts of the changing extent of the glaciers, and on the fact 'that the Glaciere is not level, and all the Ice has a Motion from the higher Parts towards the lower'. It is not possible, however, to detect in these remarks any idea resembling what we now call mass balance.

The earliest known measurements relating to mass balance were made on Rhonegletscher, Swiss Alps, beginning as early as 1874. Chen and Funk (1990) rescued these measurements from the compilation of Mercanton (1916), but they were obliged to assume a typical value for snow density, which was either not measured originally or not recorded.

Ahlmann (1935) was the first to publish a measurement of mass balance, for the balance year 1933/34 on Fourteenth of July Glacier, a calving glacier in Vestspitsbergen, Svalbard. Although ablation by calving was not estimated, the surface mass-balance rate of $-460 \mathrm{~kg} \mathrm{~m}^{-2} \mathrm{a}^{-1}$ is no more doubtful than a typical modern measurement, and it is clear that Ahlmann had an exact understanding of what was needed. Some of his terms are unfamiliar to the modern ear. For example, accumulation and ablation have their modern meanings, but the equilibrium line is the climatological firnline. His usual word for the balance is economy, with balance appearing only seldom and about as often as regime.
Wallén (1948) uses terms such as total material balance, regime and material budget. Like Ahlmann, Wallén was aware of such arcana as internal accumulation, the refreezing of surface meltwater beneath the current year's snow. He uses the terms gross ablation for the sum of all melting and evaporation, and net ablation for the sum of all meltwater runoff, evaporation and calving. The distinction between gross and net quantities is common in the early literature, but is incompatible with the terminology of Anonymous (1969), and today the adjective 'gross' appears only infrequently.

Smith (1960) refers consistently to sums of accumulation and ablation as budgets. His measurements included calving and an allowance for internal and basal melting. For Smith, gross means 'glacier-wide total', which is not consistent with Wallén's interpretation, while net accumulation and net ablation are used for the surface mass balances of the accumulation and ablation zones respectively. Hoinkes and Rudolph (1962) use net accumulation and net ablation for Smith's gross accumulation and gross ablation. They use the term mass-balance, but it is hyphenated even when used as a noun. Müller (1962) also uses hyphenated mass-balance, and sometimes mass-budget. Meier and Post (1962) call the mass balance the net budget, while Heusser and Marcus (1964) call it the hydrological budget.

These are illustrations of inconsistencies, individually harmless if the different terms are defined at their first appearance, but cumulatively confusing, that may have stimulated Meier (1962) to offer a proposal for uniform usage in the study of mass balance. The terms and the framework of that paper evolved into a near-consensus which was published as UNESCO/IASH (1970). However, the source most often cited is Anonymous (1969), a reprint of appendix 2 of UNESCO/IASH (1970) which appeared in the Journal of Glaciology.

The leading feature of Anonymous (1969) was a set of terms for mass-balance components, with definitions and recommended notation. Two 'time systems' were identified, each with a separate subset of terms. The stratigraphic system and the fixed-date system are for measurements based respectively on the roughly annual span between successive summer surfaces and on fixed field-survey dates. (At each point on the glacier, the summer surface forms at the time of annual minimum mass.) Several ancillary quantities were defined, all having a connection with the 
equilibrium line, which has long had a status almost as fundamental as the mass balance itself. Anonymous (1969) also discussed the nature of firn, and its suggested definition has been adopted widely.

Some supplementary material to UNESCO/IASH (1970) appeared as UNESCO/IASH (1973), the appendix of which also appeared as a paper by Mayo and others (1972). This was a method for combining the stratigraphic and fixed-date time systems of Anonymous (1969). The fixed-date system was referred to as the annual system by Mayo and others (1972), who introduced an extensive set of new definitions. Most of these were not adopted widely, and the main practical result was that there are now not two but four recognized time systems, the combined system and the floating-date system being added to the original two.

Anonymous (1969) soon became the informal standard for the presentation of mass-balance data. Glaciologists have got into the habit of citing it thus, although the citation baffles people from neighbouring disciplines. As for its anonymity, UNESCO/IASH (1970) is stated to have been 'prepared by a Working Group of the International Commission on Snow and Ice of the International Association of Scientific Hydrology, under the chairmanship of Dr. M.F. Meier'. Anonymous (1969) codified the thinking on which we have relied over the past 40 years for describing the components of glacier mass balance, enshrining for example $b_{\mathrm{n}}$ as the symbol for net mass balance, and $c$ and $a$ for accumulation and ablation respectively. Even its authors, one suspects, would not describe it as exciting, but that glaciologists take it for granted every day should not disqualify it from classic status, and indeed might be seen as qualifying it for such status.

The years following the International Geophysical Year of $1957 / 58$ were a golden age for environmental observation, much enhanced in glaciology by the International Hydrological Decade (IHD; 1965-74). The volume Fluctuations of glaciers 1959-1965 compiled by Kasser (1967) was a contribution to the IHD, and also a pilot study for what became the work of the Permanent Service on the Fluctuations of Glaciers and eventually of the World Glacier Monitoring Service. The development of this organizational framework was as timely as the work that led to Anonymous (1969), for the number of published mass-balance and related measurements was growing rapidly.

Organization of the flow of data has continued, for example with the development of national monitoring strategies (Fountain and others, 1997) and by transfer of skills to newly emerging glaciology programmes (Kaser and others, 2003). Among important methodological developments, the emergence of accurate techniques for measurement of the mass balance of ice sheets is particularly notable, although some of the techniques are still emerging and the time may not be ripe for standards. On the other hand, it is preferable that usage be agreed upon before the terminology of ice-sheet mass balance becomes fixed in inconsistent and ambiguous ways. Another development is that remotely sensed balance measurements, particularly by geodetic methods, are now a reality for glaciers of all sizes, and they can be expected to grow in importance. Among conceptual developments, one is the recognition of glaciers as hazards (e.g. Richardson and Reynolds 2000), and one that stands out is the recognition that glaciers participate not just in the water balances of their drainage basins but in that of the ocean (Meier, 1984).
Terminology, however, has received little systematic attention in the decades since 1969.

\section{AMBIGUITIES, GAPS AND COMPLEXITY}

Like other standards, Anonymous (1969) has been extended liberally. For example, winter and summer seasons are not defined in the fixed-date system, yet fixed-date winter and summer mass balances have been published. More seriously, the terminologies for stratigraphic and fixed-date mass balances have become entangled with each other. The terms net balance and total accumulation belong to the stratigraphic system, and annual balance and annual accumulation are the corresponding fixed-date terms. In the literature, however, phrases such as net annual balance appear regularly; net and annual are often used one for the other; and total is used occasionally with the technical meanings given in Anonymous (1969) but more often with its everyday meaning. Notwithstanding Anonymous's clear exposition of these concepts, many glaciologists have evidently found the plain-language meanings more valuable than their technical meanings.

A forthcoming update of Anonymous (1969), described in the next section, addresses this and the other difficulties discussed here.

The adjective specific causes difficulty. It has a particular meaning in mass-balance studies that is different from its meaning in some other disciplines, but glaciologists are in two minds about this particular meaning: some think it is 'at a point' while others think it is 'per unit area'. In fact Anonymous (1969) discussed units and dimensions only briefly, and the ambiguity of specific can be traced back to Meier (1962), who wrote that 'water-equivalent components ... are defined for points on a glacier (specific quantities) or as area-integrated totals for the whole glacier (total quantities)'. The two meanings of specific can be parsed out of this statement, with roughly equal validity, by attaching it either to 'point' or to 'water-equivalent'. We cannot resolve the ambiguity by investigating the meaning of 'area-integrated total', the dimension of which depends not on what specific means but on whether water-equivalent units are used (in which case the dimension is volume, $\left[\mathrm{L}^{3}\right]$ ) or not (in which case the dimension is mass, [M]). Water-equivalent quantities are implicitly quantities per unit area: $1 \mathrm{mw}$.e. is defined as $1000 \mathrm{~kg} \mathrm{~m}^{-2}$ divided by $1000 \mathrm{~kg} \mathrm{~m}^{-3}$, the density of fresh water, and $1 \mathrm{~m}^{3}$ w.e. is simply $1 \mathrm{~m}$ w.e. multiplied by $1 \mathrm{~m}^{2}$.

The advice about notation in Anonymous (1969) is firm and clear: lower-case letters such as $b$ should be used for all measurements at points, and upper-case letters such as $B$ for quantities measured over an area (such as that of the whole glacier). Most writers follow this convention, but a minority, perhaps influenced by the ambiguity of specific, believes that lower-case letters are for quantities per unit area (dimension $\left[\mathrm{ML}^{-2}\right]$ ) and upper-case letters for totals (dimension $[\mathrm{M}]$ ).

Anonymous (1969) was focused strongly on what is now called the surface mass balance. It acknowledges briefly the possible importance of the internal mass balance and suggests notation for it, but it had not often been measured at that time and indeed it is no easier to measure today than 40 years ago. More significant as a gap in coverage is that Anonymous simply noted that 'Calving may be treated separately'. The difficulty of measuring the calving rate has 
led to serious under-representation of calving glaciers in measurement programmes that rely mainly on glaciological methods. (The adjective 'glaciological' describes measurements made in situ on the glacier surface using stakes and snow pits.) Cogley (2009) found that $7 \%$ of glaciers whose mass balance was measured by glaciological methods were calving glaciers, while $32 \%$ of glaciers with measurements by geodetic methods were calving glaciers. When the newly assimilated geodetic measurements were incorporated into the calculations, the estimate of global average mass balance became significantly more negative than that obtained with the glaciological measurements alone. Calving glaciers, it seems, have been losing mass more rapidly than landterminating glaciers. Both measurement methods and terminology for ablation by calving remain underdeveloped.

G.deQ. Robin, who chaired the discussion of Meier (1962), pleaded (p.263) for a reduction in complexity: '... cumulative mass flux and things like that do not trip off the tongue frightfully easily for a non-mathematician'. The idea of glacier mass balance is fundamentally simple. It is the sum of accumulation and ablation, for a total of three technical terms. In accord with Robin's plea, the terminology set out by Anonymous (1969) was less complicated than that of Meier (1962), and the possible fate of more complicated systems is exemplified by that of Mayo and others (1972). Robin's words remind us that many workers have a professional concern with mass balance but do not use the language of mathematics regularly. It is wrong, however, to conclude that mathematics is to blame for the complexity. Complexity arises when the number of ideas in need of labels becomes large. In this respect the study of glacier mass balance is probably committed to a steady rise in the number of labels.

The unstated principle underlying Anonymous (1969), that ideas and labels should ideally be in one-to-one correspondence, is probably a good principle for a field facing steady growth of complexity.

\section{A NEW LOOK AT MASS-BALANCE TERMINOLOGY}

During 2011, the International Association of Cryospheric Sciences (IACS) will publish, as a UNESCO Technical Document in Hydrology, a Glossary of glacier mass balance and related terms compiled by its Working Group on Massbalance Terminology and Methods. The Working Group was constituted in March 2008. The aim of the Glossary is to update and revise the effective standard. Anonymous (1969) has served glaciology well for 40 years, but with the passage of decades practice with conventional measurement tools has evolved, new tools have become available, and understanding of glacier mass balance and its context has improved. The scope of the Glossary is therefore necessarily broader than that of Anonymous (1969). It extends to 125 pages and about 450 articles, the latter varying from terse definitions to detailed examinations of some of the fundamental ideas.

The Glossary represents a consensus among a group of practising glaciologists who have tried to steer a middle course between being prescriptive, that is, laying down the law about how terms are to be used, and being descriptive, that is, simply recording the facts of current usage.

For example, the Glossary takes a firm position on the meanings of area and Julian day number. The first is sometimes and the second often used in a way which is mistaken. In mass-balance studies, lengths such as layer thicknesses are always measured parallel to the vertical axis and not normal to the glacier surface. When calculating volumes, the area to be used is therefore not sec $\alpha \mathrm{d} s$, which is the area of a patch of surface with slope $\alpha$. The correct area is $d s$, an element of horizontal or projected area. The Julian day number is not the day of the year, which ranges from 1 to 365 or 366 , but rather the integer part of the number of days elapsed since a date in the distant past (explained in the Glossary). Neither of these mistakes is helpful, the first being harmful, and the Glossary asserts that both terms ought to be used correctly.

On the other hand, the Glossary accepts that some technical terms have more than one meaning, and simply records the variants. Examples include snow and firn. Anonymous (1969) defines firn as 'snow that has passed through one summer'. This definition, in which snow becomes firn at the last instant of the mass-balance year, is adopted almost universally in discussions of mass balance, but there is also a structural definition in which firn is the metamorphic stage intermediate between snow and ice.

An example of a pair of terms requiring awareness and clear understanding, rather than prescriptive or descriptive definitions, is internal accumulation and refreezing. The internal refers to accumulation of refreezing meltwater beneath the summer surface, while refreezing also includes refreezing in the snow of the current mass-balance year. The summer surface is fundamental in the glaciological method of measurement, because refreezing above the summer surface is captured by glaciological measurements and internal accumulation is not. Many newer methods, however, are unable to see the summer surface, and in massbalance modelling the summer surface is not always represented explicitly. The risk of misunderstanding between practitioners using the different methods and models seems rather high.

The Glossary addresses the ambiguity that has grown up around the valuable idea of a time system, discussed in the previous section, by recommending that the two separate terminologies of Anonymous (1969) be replaced with a single set of terms. This, it is hoped, will encourage authors to be explicit about which time system is in use, and will make descriptions of methods clearer.

The ambiguity of specific is resolved in the Glossary by recommending that it be understood to mean 'per unit area'. This recommendation is somewhat arbitrary, but one consideration in its favour is that the adjective point is a clear, short alternative to the other possible definition of specific. The Glossary simply reaffirms the recommendation of Anonymous (1969) about lower-case and upper-case letters. The Working Group has made a special effort to cover the terminology of ice-sheet mass balance, and especially of calving, with an eye to the desirability of a common language for the study of ice bodies of all sizes.

This update has not been accomplished without contributing to the growth of terminological complexity. The number of balance-related ideas is larger now than in the 1960s, and therefore so is the number of labels. But the truth remains that the essence of the subject is captured today, as it was in the 1960s and indeed at the time of the pioneering measurements reported by Mercanton (1916) and Ahlmann (1935), in just three technical terms: mass balance = accumulation + ablation. 


\section{CODA}

Those in search of wit had better look elsewhere than in Anonymous (1969), and they will not find it in the forthcoming Glossary of glacier mass balance and related terms either. Nevertheless, the search for clarity in the labels we give to ideas does have its humorous, even ridiculous, side.

It is difficult to keep a straight face throughout the preparation of a 125-page glossary. One temptation resisted successfully by the Working Group was the proposal, from a group member who shall remain nameless like Anonymous but who is affiliated with the University of Washington, that the Glossary should include the definition

Lacigology: Analysis of englacial flow patterns to discern conditions in which isochrones at successive depths do or do not have monotonically increasing ages.

The Working Group found it easier to resist the temptation after the proposer confessed that the adjectival form of lacigology is lacigological, 'which at 13 letters would surpass "tattarrattat", a nonce-word appearing in James Joyce's Ulysses, as the longest palindromic word in the Oxford English Dictionary'.

It is also difficult to mount a defence against the charge that definers of terms are policing other people's thoughts. At one meeting at which the Working Group solicited comments from fellow glaciologists, a colleague giving a subsequent talk was sufficiently offended by the forthcoming revision of terminology, or perhaps just rattled, that he said cauliflower whenever mass balance appeared in his script.

Yet everybody knew what he meant. The human mind is adept at matching labels to their ideas. Unfortunately it is also adept at believing in simultaneous conflicting, or at least discordant, ideas. This includes allowing words to mean several different things, and to mean something other than what they seem to say. One example of the latter is snowline, which at times, particularly in studies of largescale glacier-climate relations, refers not to a line on the mountainside but to a continuous surface that may or may not intersect the mountainsides in places. A more extreme example, however, is mass balance. Its counterparts, 'water balance' and 'energy balance', denote relationships, but mass balance actually means its opposite, change of storage or 'mass imbalance' (that is, only one of the terms in the relationship). No doubt there is an echo here of the everyday term 'bank balance'.

The older term mass budget does not suffer from this quirk. It was used by Meier (1962) but has been largely supplanted in modern usage by the mass balance of Anonymous (1969), perhaps because mass balance translates naturally into several European languages (e.g. bilan de masse, Massenbilanz, massebalanse and balans massy), while the translations of mass budget are more variable and less obvious. The oddity of mass balance is a striking illustration of the proposition that labels do not need to be sensible to be understood.

Nevertheless, the Working Group takes heart from the opinion on these matters of Bacon (1606, 2.XIV.11):

certain it is that words, as a Tartar's bow, do shoot back upon the understanding of the wisest, and mightily entangle and pervert the judgement. So as it is almost necessary, in all controversies and disputations, to imitate the wisdom of the mathematicians, in setting down in the very beginning the definitions of our words and terms, that others may know how we accept and understand them, and whether they concur with us or no. For it cometh to pass, for want of this, that we are sure to end there where we ought to have begun, which is, in questions and differences about words.

The emphasis has been added. One might also emphasize that Bacon's advice helps us to know whether we concur with ourselves or no. That is, defining our terms is a good way to purge our minds of discordant ideas.

The purpose of a glossary or dictionary is not to lay down the law. Dictionaries sometimes acquire authority, as among players of Scrabble ${ }^{\mathbb{R}}$, but the authority is conferred by those who look up words in them, not assumed by the harmless drudges who compile them (Johnson, 1755). In an ideal world, all users of labels would share a common understanding of all the labels. The aim of the forthcoming IACS Glossary therefore remains the same as that articulated by Anonymous (1969): to promote clarity and reduce ambiguity in the interest of common understanding.

\section{ACKNOWLEDGEMENTS}

I am grateful to G.K.C. Clarke for the invitation to write a commentary on Anonymous (1969); to my fellow lexicographers (as defined by Dr Johnson; see, e.g., http:// www.samueljohnson.com/definitions.html) in the IACS Working Group on Mass-balance Terminology and Methods: A.A. Arendt, A. Bauder, R.J. Braithwaite, R. Hock, P. Jansson, G. Kaser, M. Möller, L. Nicholson, L.A. Rasmussen and M. Zemp; and to M.F. Meier for worrying about the meaning of mass balance while I was still in school.

\section{REFERENCES}

Ahlmann, H.W. 1935. Scientific results of the Norwegian-Swedish Spitsbergen expedition in 1934. Part 5: the Fourteenth of July glacier. Geogr. Ann., 17(3-4), 167-218.

Anonymous. 1969. Mass-balance terms. J. Glaciol., 8(52), 3-7.

Bacon, F. 1906 [1606]. The advancement of learning, ed. Case, T. Oxford, Oxford University Press.

Chen, J. and M. Funk. 1990. Mass balance of Rhonegletscher during 1882/83-1986/87. J. Glaciol., 36(123), 199-209.

Cogley, J.G. 2009. Geodetic and direct mass-balance measurements: comparison and joint analysis. Ann. Glaciol., 50(50), 96-100.

Fountain, A.G., R.M. Krimmel and D.C. Trabant. 1997. A strategy for monitoring glaciers. USGS Circ. 1132.

Heusser, C.J. and M.G. Marcus. 1964. Surface movement, hydrological change and equilibrium flow on Lemon Creek Glacier, Alaska. J. Glaciol., 5(37), 61-75.

Hoinkes, H. and R. Rudolph. 1962. Variations in the mass-balance of Hintereisferner (Oetztal Alps), 1952-1961, and their relation to variations of climatic elements. IASH Publ. 58 (Symposium at Obergurgl 1962 - Variations of the Regime of Existing Glaciers), 16-28.

Johnson, S. 1755. A dictionary of the English language. London

Kaser, G., A. Fountain and P. Jansson. 2003. A manual for monitoring the mass balance of mountain glaciers: with particular attention to low latitude characteristics. Paris, UNESCO. International Hydrological Programme. (Technical Documents in Hydrology 59.)

Kasser, P., ed. 1967. Fluctuations of glaciers 1959-1965 [Vol. I]. Paris, IAHS(ICSI)-UNESCO.

Mayo, L.R., M.F. Meier and W.V. Tangborn. 1972. A system to combine stratigraphic and annual mass-balance systems: a 
contribution to the International Hydrological Decade. J. Glaciol., 11(61), 3-14.

Meier, M.F. 1962. Proposed definitions for glacier mass budget terms. J. Glaciol., 4(33), 252-263.

Meier, M.F. 1984. Contribution of small glaciers to global sea level. Science, 226(4681), 1418-1421.

Meier, M.F. and A.S. Post. 1962. Recent variations in mass net budgets of glaciers in western North America. IASH Publ. 58 (Symposium at Obergurgl 1962 - Variations of the Regime of Existing Glaciers), 63-77.

Mercanton, P.L., ed. 1916. Vermessungen am Rhonegletscher/ Mensuration au glacier du Rhône: 1874-1915. Neue Denkschr. Schweiz. Naturforsch. Ges. 52.

Müller, F. 1962. Glacier mass-budget studies on Axel Heiberg Island, Canadian Arctic Archipelago. IASH Publ. 58 (Symposium at Obergurgl 1962 - Variations of the Regime of Existing Glaciers), 131-142.

Richardson, S.D. and J.M. Reynolds. 2000. An overview of glacial hazards in the Himalayas. Quat. Int., 65/66(1), 31-47.
Rowlinson, J.S. 1998. 'Our common room in Geneva' and the early exploration of the Alps of Savoy. Notes Rec. R. Soc. Lond., 52(2), 221-235.

Smith, J. 1960. Glacier problems in South Georgia. J. Glaciol., 3(28), 705-714.

UNESCO/International Association of Scientific Hydrology (IASH). 1970. Combined heat, ice and water balances at selected glacier basins: a guide for compilation and assemblage of data for glacier mass balance measurements. Paris, UNESCO/IASH. (Technical Papers in Hydrology 5, Part 1.)

UNESCO/IASH. 1973. Combined heat, ice and water balances at selected glacier basins: specifications, standards and data exchange. Paris, UNESCO/IASH. (Technical Papers in Hydrology 5, Part 2.)

Wallén, C.C. 1948. Glacial-meteorological investigations on the Kårsa glacier in Swedish Lappland. Geogr. Ann., 30(3-4), 451-672.

Windham, W. and P. Martel. 1744. An account of the glacieres or ice Alps in Savoy. London. 